\title{
Contribution to the FEM simulation of Ti6Al4V Machining
}

\author{
Marek Vrabel ${ }^{1, *}$, Numan Durakbasa ${ }^{2}$, Pavel Kovač ${ }^{3}$ and Ildikó Maňková ${ }^{4}$ \\ ${ }^{1}$ Technical University of Košice, Faculty of Mechanical Engineering, Department of Manufacturing Technology and Materials, Mäsiarska 74, 04001 \\ Kosice, Slovakia \\ ${ }^{2}$ Institute for Production Engineering and Laser Technology, Vienna University of Technology, Getreidemarkt 9, 1060 Wien, Austria \\ ${ }^{3}$ Faculty of Technical Sciences, Dositeja Obradovića 6, 21000 Novi Sad, Serbia \\ ${ }^{4}$ Technical University of Košice, Faculty of Mechanical Engineering, Department of Computer Support of Technology, Mäsiarska 74, 04001 Kosice, \\ Slovakia
}

\begin{abstract}
The paper briefly reviews current scientific publications related to machining of difficult to cut materials and finite element modelling methods (FEM) applied in various chip making processes. Simulations of the orthogonal machining process with regard to define optimal cutting parameters as well as cutting wedge geometry in hole making TiAIN alloy was performed according to test plan based on design of experiment (DoE) methodology. The numerical simulations were performed using commercial finite element software (AdvantEgde), which is suitable to solve complex thermo-mechanical problems occurring in cutting zone during chip making process. A Lagrangian finite element-based model is applied within simulation procedure. Results from experimental simulation were evaluated by main effect and surface response plots.
\end{abstract}

Keywords: Design of experiment (DoE); finite element method (FEM); response surface methodology (RSM); titanium alloys; tool geometry.

\section{Introduction}

In modern manufacturing industry it is essential to produce under low costs and high quality of products in a short time. It is well known that cutting tools are subjected to high stresses by modern machining technologies, like dry machining, high-speed machining or high-performance machining [1]. Moreover, the requirements in quality of the finished product, decrease of costs, flexibility, reduced times of production, productivity, capacity to process new materials and miniaturization are among others. [2], [3]. High material removal rate, high cutting parameters requires high tool performance. Therefore, the geometry of the cutting edge, and its preparation, play a significant role on the performance of a cutting tool when machining widely used or difficult-to-machine materials [4], [5]. Ti6Al4V titanium alloy is often used not only in the aircraft industry due to the good compromise between mechanical resistance and tenacity, together with its low density and excellent corrosion resistance. However, this material is known to be difficult to machine. One of the reasons is due to its low thermal conductivity which gives rise to high pressures and temperatures at the tool-chip interface, a plastic instability localized in adiabatic shear bands, tool wear by thermal fatigue and diffusion. [6], [7], [8]. In order to increase productivity and tool life in the machining of titanium alloys, it is necessary to develop a reliable FE model for conventional 
cutting speed regime. To accurately analyze this process using numerical methods such as Finite Element Analysis (FEA) the knowledge of material constitutive behaviour under these severe loading conditions is a pre-requisite. Finite element analysis is preferred than the laborious experimental work in order to save time and cost. Researchers have previously concluded that the results obtained from finite element analysis stays close to the experimental results. Kumar [8] concluded that, as the included angle between the cutting edges decreases, the wear depth and cutting forces are getting reduced. i. e. when the shape is changed from $90^{\circ}$ to $55^{\circ}$. Sasahara et al. [9] used finite element method to develop a process model and investigated the effects of corner radius and feed rates in a face turning process. Their results showed that residual stresses changed from tension to compression as feed rate decreases and as the corner radius become smaller. Yung-Chang Yen et all. [10] has shown how various tool geometries like round/hone edge and T-land/chamfer edge affects process variables, while machining AISI 1020 by uncoated cemented carbide using FEM cutting simulation. Matsumura et all. [11] presented hybrid simulation of drilling to save the time for analysis. In the hybrid simulation, the FE analysis is conducted in a 2D model determined by the energy analysis for the cutting force prediction as well as for surface quality. Selected results of experimental and simulation processes for cutting forces are illustrated in Table 1 when machining titanium alloy Ti6Al4V.

This paper presents the application of Finite

Table 1: State of the art of experimental and simulation data for cutting forces and temperature when machining titanium alloy Ti-6Al-4V.

\begin{tabular}{|c|c|c|c|c|c|c|c|c|}
\hline Author & Tool material & Tool geometry $\left[{ }^{\circ}\right]$ & Cutting Conditions & $\begin{array}{l}\text { Exp. } \\
F x[N]\end{array}$ & $\begin{array}{l}\text { Sim. } \\
F x[N]\end{array}$ & $\begin{array}{l}\text { Exp. } \\
\text { Fy [N] }\end{array}$ & $\begin{array}{l}\text { Sim. } \\
\text { Fy }[N]\end{array}$ & $\begin{array}{l}\text { Sim. } \\
T\left[{ }^{\circ} \mathrm{C}\right]\end{array}$ \\
\hline $\begin{array}{l}\text { Calamaz et al. } \\
2008 \text { [6] }\end{array}$ & Uncoated carbide & $\begin{array}{l}\gamma=-4, \alpha=7 \\
r_{n}=20[\mu \mathrm{m}]\end{array}$ & $\begin{array}{l}v_{c}=180 \mathrm{~m} / \mathrm{min} \\
f=0,1 \mathrm{~mm}\end{array}$ & - & - & 550 & 300 & 700 \\
\hline $\begin{array}{l}\text { Ulutan et al. } \\
2013 \text { [12] }\end{array}$ & Uncoated carbide & $\begin{array}{l}\gamma=-5 \\
\mathrm{rn}=20[\mu \mathrm{m}]\end{array}$ & $\begin{array}{l}\mathrm{v}_{\mathrm{c}}=120 \mathrm{~m} / \mathrm{min} \\
\mathrm{ap}=5 \mathrm{~mm}\end{array}$ & 240 & 245 & 495 & 520 & - \\
\hline $\begin{array}{l}\text { Weyn et al. } \\
2010 \text { [13] }\end{array}$ & Uncoated carbide & $\begin{array}{l}\gamma=-10, \alpha=8 \\
\mathrm{rn}_{\mathrm{n}}=10[\mu \mathrm{m}]\end{array}$ & $\begin{array}{l}v_{c}=120 \mathrm{~m} / \mathrm{min} \\
\mathrm{f}=0,06 \mathrm{~mm}\end{array}$ & 40 & - & 120 & - & \\
\hline $\begin{array}{l}\text { Constantin et al. } \\
2012 \text { [14] }\end{array}$ & Uncoated carbide & $\begin{array}{l}\gamma=0, \alpha=11 \\
\mathrm{r}_{\mathrm{n}}=10[\mu \mathrm{m}]\end{array}$ & $\begin{array}{l}V_{c}=150 \mathrm{~m} / \mathrm{min} \\
\mathrm{f}=0,1 \mathrm{~mm}\end{array}$ & - & 225 & - & 100 & 450 \\
\hline $\begin{array}{l}\text { Özel. et al. } \\
2010 \text { [15] }\end{array}$ & Uncoated carbide & $\begin{array}{l}\alpha=11, \gamma=-5 \\
r_{n}=5[\mu \mathrm{m}]\end{array}$ & $\begin{array}{l}\mathrm{v} c_{\mathrm{c}}=100 \mathrm{~m} / \mathrm{min} \\
\mathrm{ap}=2 \mathrm{~mm}\end{array}$ & 380 & 229 & 750 & 590 & 785 \\
\hline \multirow[t]{2}{*}{$\begin{array}{l}\text { Lazoglu et all } \\
2016 \text { [16] }\end{array}$} & \multirow[t]{2}{*}{ Uncoated carbide } & \multirow[t]{2}{*}{ Twist drill } & $\begin{array}{l}v_{c}=10 \mathrm{~m} / \mathrm{min} \\
\mathrm{f}=0,1 \mathrm{~mm}\end{array}$ & & & & & 370 \\
\hline & & & $\begin{array}{l}v_{c}=30 \mathrm{~m} / \mathrm{min} \\
\mathrm{f}=0,2 \mathrm{~mm}\end{array}$ & & & & & 550 \\
\hline
\end{tabular}

Element Method (FEM) to study the effect of tool geometry and cutting conditions of uncoated carbide cutting tool WC/Co (rake angle, cutting edge radius) on cutting force (Fx, Fy) and temperature $(T)$ in the orthogonal machining process of titanium alloy Ti6Al4V, under dry cutting conditions when using machining parameter variables cutting speed and feed.

\section{Experimental Setup and Simulation Methodology of AdvantEdge}

One of the important parameters in the orthogonal metal cutting process is the rake angle between the face of the cutting tool and the plane perpendicular to the cutting direction [9]. The effect of cutting edge radius and rake angle on the cutting force and temperature has been studied. A Lagrangian finite element-based model is applied in the simulation of cutting forces and temperature in two-dimensional orthogonal metal cutting of titanium Ti6Al4V alloy. Chemical composition of the titanium alloy is listed in Table 2.

The simulations were performed using Third Wave AdvantEdge Systems software. The cutting 
Table 2: Chemical composition of Ti6Al4V.

\begin{tabular}{|l|l|l|l|l|l|l|l|}
\hline Material & Ii & Al & V & Fe & 0 & C & N \\
\hline Ti-6Al-4V (\%) & Balance & 6.01 & 3.87 & 0.18 & 0.14 & 0.009 & 0.006 \\
\hline
\end{tabular}

Table 3: Simulation input parameters.

\begin{tabular}{|c|c|c|c|c|}
\hline \multicolumn{2}{|l|}{ Parameter } & Symbol & Unit & Value \\
\hline \multirow{2}{*}{ 产 : } & Workpiece length & IW & {$[\mathrm{mm}]$} & 5,0 \\
\hline & Workpiece height & hw & {$[\mathrm{mm}]$} & 2,0 \\
\hline \multirow{8}{*}{ 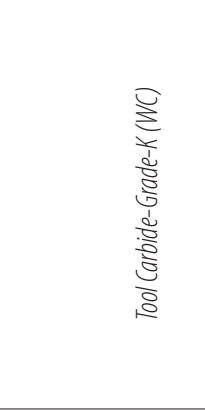 } & Rake angle & Y & {$\left[{ }^{\circ}\right]$} & $5 ; 10 ; 15$ \\
\hline & Rake length & ly & {$[\mathrm{mm}]$} & 2,0 \\
\hline & Relief angle & a & {$\left[{ }^{\circ}\right]$} & 10 \\
\hline & Relief length & la & {$[\mathrm{mm}]$} & 2,0 \\
\hline & Cutting Edge Radius & $r_{n}$ & {$[\mu \mathrm{m}]$} & $20 ; 50 ; 80$ \\
\hline & Min. Tool Element Size & - & {$[\mathrm{mm}]$} & 0,02 \\
\hline & Max. Tool Element Size & - & {$[\mathrm{mm}]$} & 0,1 \\
\hline & Mesh Grading & - & - & 0,4 \\
\hline \multirow{6}{*}{ 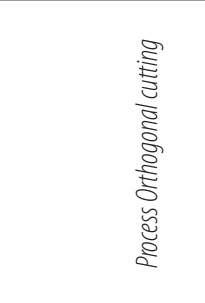 } & Depth of cut & doc & {$[\mathrm{mm}]$} & 1,0 \\
\hline & Length of cut & loc & {$[\mathrm{mm}]$} & 3,0 \\
\hline & Feed & $f$ & {$[\mathrm{~mm}]$} & 0,$05 ; 0,1 ; 0,15$ \\
\hline & Cutting speed & $\mathrm{Vc}$ & {$[\mathrm{m} / \mathrm{min}]$} & $30 ; 90 ; 120$ \\
\hline & Initial temperature & $\mathrm{T}$ & {$\left[{ }^{\circ}\right]$} & 20 \\
\hline & Friction coefficient & $\mu$ & - & 0,5 \\
\hline
\end{tabular}

Table 4: Initial machining parameters.

\begin{tabular}{|c|c|c|c|c|c|}
\hline \multirow{2}{*}{ Factors } & \multirow{2}{*}{ Symbol } & \multirow{2}{*}{ Unit } & \multicolumn{3}{|c|}{ Cutting conditions } \\
\hline & & & Level 1 & Level 2 & Level 3 \\
\hline Cutting speed & Ve & {$[\mathrm{m} / \mathrm{min}]$} & 30 & 90 & 120 \\
\hline Feed & f & {$[\mathrm{mm} / \mathrm{rev}]$} & 0,05 & 0,10 & 0,15 \\
\hline Cutting edge radius & $r_{n}$ & {$[\mu \mathrm{m}]$} & 20 & 50 & 80 \\
\hline Rake angle & $\gamma$ & {$\left[{ }^{\circ}\right]$} & -5 & -10 & -15 \\
\hline
\end{tabular}

Table 5: Taguchi orthogonal array design $L 9$ with simulation output characteristics.

\begin{tabular}{|c|c|c|c|c|c|c|c|}
\hline Exp & $\begin{array}{c}\text { Cutting speed } \\
v_{c}[\mathrm{~m} / \mathrm{min}]\end{array}$ & Feed $[\mathrm{mm}]$ & $\begin{array}{c}\text { Cutting edge radius } \\
\qquad r_{n}[\mu \mathrm{m}]\end{array}$ & Rake angle $\gamma\left[^{\circ}\right]$ & $\begin{array}{c}\text { Feed force } \\
\text { Fx }[N]\end{array}$ & $\begin{array}{c}\text { Cutting force } \\
\text { Fy }[N]\end{array}$ & Temp. $T\left[^{\circ} \mathrm{C}\right]$ \\
\hline 1 & 30 & 0,05 & 20 & -5 & 130 & 109 & 452 \\
\hline 2 & 30 & 0,10 & 50 & -10 & 220 & 184 & 523 \\
\hline 3 & 30 & 0,15 & 80 & -15 & 290 & 246 & 573 \\
\hline 4 & 90 & 0,05 & 50 & -15 & 125 & 165 & 679 \\
\hline 5 & 90 & 0,10 & 80 & -5 & 235 & 271 & 822 \\
\hline 6 & 90 & 0,15 & 20 & -10 & 251 & 121 & 862 \\
\hline 7 & 120 & 0,05 & 80 & -10 & 146 & 256 & 925 \\
\hline 8 & 120 & 0,10 & 20 & -15 & 174 & 97 & 869 \\
\hline 9 & 120 & 0,15 & 50 & -5 & 271 & 199 & 1065 \\
\hline
\end{tabular}


tool material employed was cemented carbide grade $\mathrm{K}(\mathrm{WC} / \mathrm{Co})$. The initial temperature for the work piece and tool is set as $20^{\circ} \mathrm{C}$ (room temperature). Coefficient of friction was set to 0.5 by default. Machining parameters (cutting speed and feed), and cutting tool geometry (rake angle and cutting edge radius) were considered as variables. Machining parameter such as clearance angle $(\alpha)$ and depth of cut (doc) were kept constant at $10^{\circ}$ and $1 \mathrm{~mm}$, respectively. The input values to simulation process are given in Tab. 3 .

Design of experiment (DoE) is a powerful statistical method for determining the unknown properties of the machining parameters in the experiment process and for analyzing and modeling the interaction among the factors. Taguchi method also allows controlling the variations caused by the uncontrollable factors which are not taken into consideration at conventional design of experiment [8], [17], [18].

In this study, machining experiments are planned using Taguchi L9 $\left(3^{4}\right)$ orthogonal array with output characteristics of cutting forces Fx and Fy and temperature $T$ which were obtained by means of FEM simulations listed in Table 5. Experimental tests are conducted by considering four machining parameters: cutting speed, feed, cutting edge radius and rake angle at three levels as shown in Table 4.

\section{Results and Discussion}

Analysis of simulation output parameters was performed in Tecplot 360 software. Statistical software Minitab 16 and Matlab R2012 was employed to process and evaluate of experimental data. The experimental results based on the orthogonal array are then transformed into analysis of the Main effect of means to evaluate the performance characteristics. Finally, the desirability function approach is used in the optimization of multiple-response surfaces through RSM method.

Values of cutting forces in $X$ and $Y$ directions and temperature were obtained at varying cutting conditions as listed in Table 4. Fig. 1 shows the plots of feed force Fx and cutting force Fy of Exp. 3 and Exp. 5, respectively. The maximum achieved feed force and cutting force were approximately $290 \mathrm{~N}$ and $271 \mathrm{~N}$, at Exp. 3 and Exp. 5, respectively. Fig. 2 shows the temperature distribution on tool edge of Exp. 3 and Exp. 5, respectively. The maximum achieved temperature were approximately $1065^{\circ} \mathrm{C}$ at Exp. 9. The largest peak temperature achieved in Exp. 9, it is attributed to adjusting cutting speed $v_{c}=120 \mathrm{~m} / \mathrm{min}$ and feed $\mathrm{f}=0.15 \mathrm{~mm}$, which represents the highest value.
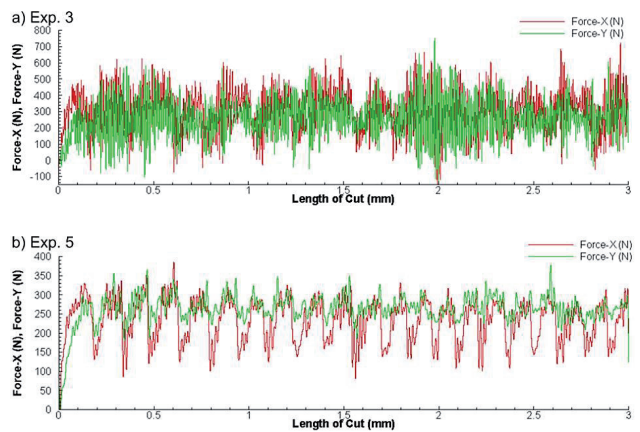

Fig. 1: Cutting Force (Fx, Fy) as a function of length of cut: (a) Exp. 3, (b) Exp. 5 .

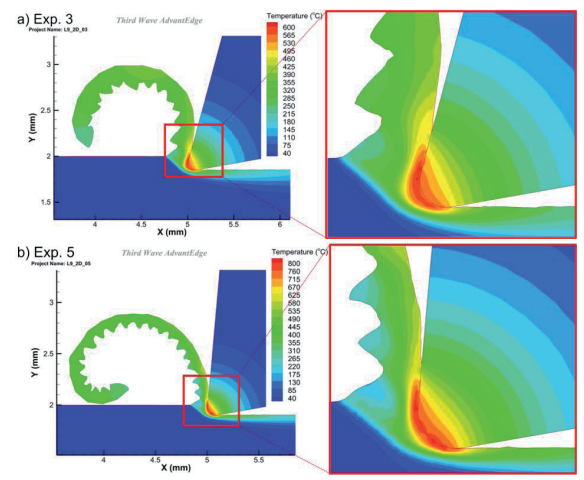

Fig. 2: Temperature ( $T$ ) as a function of length of cut: (a) Exp. 3, (b) Exp. 5 .

\subsection{Analysis and evaluation of results using Taguchi design}

The values of the significant factors for feed force Fx, cutting force Fy and temperature $T$ were given in the Table 6, 7 and 8 and Fig. 3 can be used to estimate the mean cutting force and temperature with optimal performance conditions. Two factors were found to be significant in both Fx and Fy for Response table for Means analysis that is feed and cutting edge radius, which gave the smallest cutting forces values. Two factors were found to be significant in temperature $T$ for Response table for Means analysis that is cutting speed and feed, which gave the smallest temperature values. To determine the interaction effects of machining parameters on cutting forces and temperature, the individual 
Table 6: Taguchi orthogonal array design Lo with simulation output characteristics

\begin{tabular}{|l|l|l|l|l|}
\hline Level & Cutting speed $\mathbf{v}_{\boldsymbol{c}}[\mathrm{m} / \mathbf{m i n}]$ & Feedf $[\mathrm{mm}]$ & Cutting edge radius $\boldsymbol{r}_{\boldsymbol{n}}[\boldsymbol{\mu m}]$ & Rake angle $\left.{ }{ }^{\circ}\right]$ \\
\hline 1 & 230,3 & 138,7 & 198,3 & 209,7 \\
\hline 2 & 216 & 222,3 & 214 & 221,7 \\
\hline 3 & 207 & 292,3 & 241 & 222 \\
\hline Delta & 23,3 & 153,7 & 42,7 & 12,3 \\
\hline Rank & 3 & 1 & 2 & 4 \\
\hline
\end{tabular}

Table 7: Response table for Means for feed force Fx.

\begin{tabular}{|l|l|l|l|l|}
\hline Level & Cutting speed $\boldsymbol{v}_{\boldsymbol{c}}[\mathrm{m} / \mathrm{min}]$ & Feed $[\mathrm{mm}]$ & Cutting edge radius $\boldsymbol{r}_{\boldsymbol{n}}[\boldsymbol{\mu m}]$ & Rake angle $\gamma\left[^{\circ}\right]$ \\
\hline 1 & 196,7 & 181 & 117,7 & 183,7 \\
\hline 2 & 192,7 & 191 & 191 & 196,7 \\
\hline 3 & 191 & 208,3 & 271,7 & 200 \\
\hline Delta & 5,7 & 27,3 & 154 & 16,3 \\
\hline Rank & 4 & 2 & 1 & 3 \\
\hline
\end{tabular}

Table 8: Response table for Means for cutting force Fy.

\begin{tabular}{|l|l|l|l|l|}
\hline Level & Cutting speed $\mathbf{v}_{\boldsymbol{c}}[\mathbf{m} / \mathbf{m i n}]$ & Feedf $[\mathbf{m m}]$ & Cutting edge radius $\boldsymbol{r}_{\boldsymbol{n}}[\boldsymbol{\mu m}]$ & Rake angle $\boldsymbol{\gamma}\left[^{\circ}\right]$ \\
\hline 1 & 516 & 685,3 & 727,7 & 707 \\
\hline 2 & 787,7 & 738 & 755,7 & 770 \\
\hline 3 & 953 & 833,3 & 773,3 & 779,7 \\
\hline Delta & 437 & 148 & 45,7 & 72,7 \\
\hline Rank & 1 & 2 & 4 & 3 \\
\hline
\end{tabular}
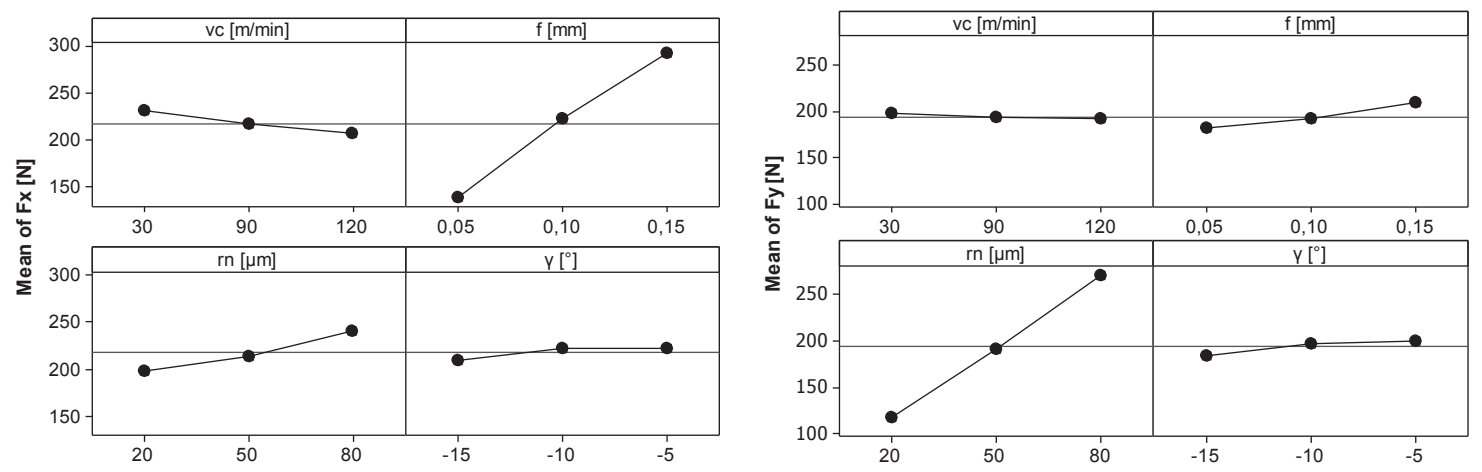

Fig. 3: Main effect plot for Means of feed and cutting forces (a) (Fx). (b) (Fy).

input parameters were ranked. Response table for Means and ranked factors for cutting force Fx and Fy and temperature $T$ are listed in Table 6, 7 and 8, respectively. The presented values (Table 6, 7 and 8 ) show the Means at each level of the control factors and how it is changed when settings of each control factor are changed from one level to another. Based on Taguchi prediction the smallest values of Means have more significant effect on cutting forces Fx, Fy and $T$, respectively.

When feed force Fx is considered, from Tab. 6, the feed is listed to have a strong effect on feed force Fx. The second significant parameter is cutting edge radius. The other two examined parameters like cutting speed and rake angle have no significant effect on feed force. From the response table for 
means analysis, the optimal cutting parameters for feed force Fx were determined as $\mathrm{f}_{1}=0,05 \mathrm{~mm}, \mathrm{r}_{\mathrm{n} 1}=$ $20 \mu \mathrm{m}, \mathrm{v}_{\mathrm{c} 3}=120 \mathrm{~m} / \mathrm{min}$ and $\gamma_{1}=-15^{\circ}$, respectively.

When cutting force Fy is considered, from Tab. 7, the cutting edge radius is listed to have a strong effect on cutting force Fy. The second significant parameter is feed. The other two examined parameters like rake angle and cutting speed have no significant effect on cutting force. From the response table for means analysis, the optimal cutting parameters for cutting force Fy were determined as $\mathrm{r}_{\mathrm{n} 1}=20 \mu \mathrm{m}, \mathrm{f}_{1}=0,05 \mathrm{~mm}$. $\mathrm{v}_{\mathrm{c} 3}=$ $120 \mathrm{~m} / \mathrm{min}$ and $\gamma_{1}=-15^{\circ}$, respectively.

When temperature $T$ is considered, from Tab. 8, the cutting speed is listed to have a strong effect on temperature $T$. The second significant parameter is feed. The other two examined parameters rake angle and cutting edge radius have no significant effect on temperature. The optimal cutting parameters for temperature $T$ were determined as $v_{c 1}=30 \mathrm{~m} / \mathrm{min}$, $f_{1}=0,05 \mathrm{~mm}, \gamma_{1}=-15^{\circ}$ and $r_{n 1}=20 \mu \mathrm{m}$, respectively.

Fig. 3 shows the main effect plot for Means of cutting forces Fx, Fy and Temperature T, respectively. Main effect plot for Means (Smaller is Better) shows the sharply slope towards to the biggest value at feed and cutting edge radius, which have the most significant effect on feed force Fx and cutting force Fy), respectively. The results further indicate that increasing of feed increases the feed force Fx while for cutting force Fy increases with increasing cutting edge radius. However, cutting speed and rake angle has no significant effect on the cutting force Fx and Fy.

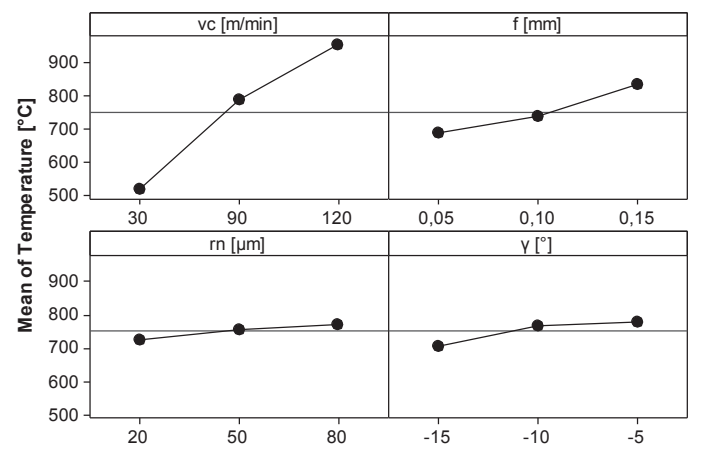

Fig. 4: Main effect plot for Means of temperature (T).

Fig.4 shows sharply slope towards to the biggest value at cutting speed, which have the most significant effect on temperature T. The second significant parameter is feed. Note that cutting edge radius and rake angle has no significant effect on temperature $\mathrm{T}$.

The 3D response surface plots for feed force Fx, cutting force Fy and temperature $T$ are shown on Fig.5. As the model is adequate these 3D surface plots can be used for estimating the cutting force and temperature for the any suitable combination of the input parameters namely cutting speed, feed, cutting edge radius and rake angle.

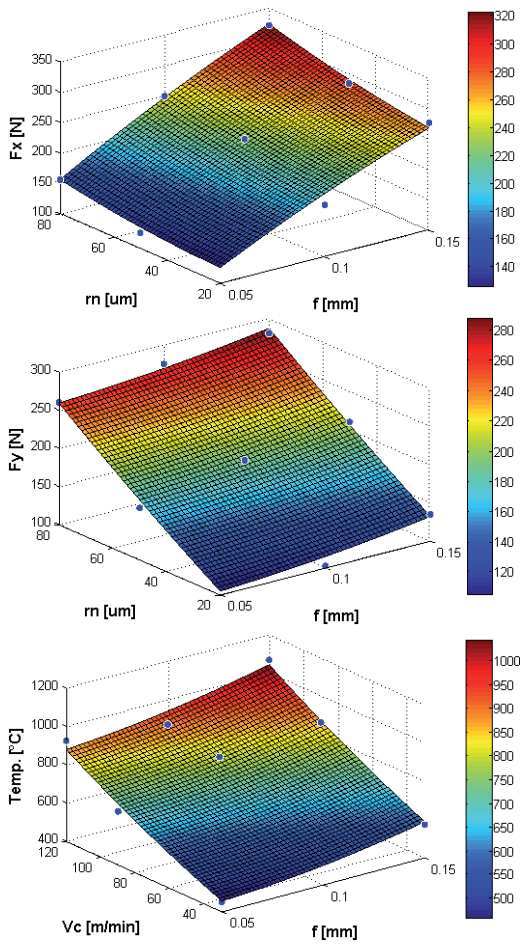

Fig. 5: The 3D response surface plots of feed force (Fx) cutting force (Fy) and temperature (T) vs. cutting edge radius ( $r n$ ) and feed ( $f$ ).

It is clear from Fig. 5 that the feed force Fx decreases with decreasing cutting edge radius. Minimal values of feed force Fx can be obtained with a smaller feed, and cutting edge radius has smaller significant effect on feed force Fx. Results revealed that smaller value of cutting edge radius decreases value of cutting force Fy, while the cutting edge radius has the most significant effect and feed has smaller significant effect on cutting force Fy. The results further indicate that increasing of cutting speed increasing the temperature $T$, while the feed has less significant effect on temperature $T$ are shown in Fig. 5. 


\section{Conclusions}

This paper focuses on Taguchi method and response surface methodology (RSM) for investigating of influence of the cutting parameters on the cutting forces and temperature when orthogonal cutting of titanium alloy Ti6Al4V. In the simulation, different cutting speed, feed, cutting edge radius and rake angle values are used. Results were evaluated using the analysis of main effect graphs of means (smaller is better). Optimal operating parameters are determined using the Taguchi method, RSM function. The results can be drawn as follows:

- The simulation results were analyzed using main effect graphs of means. For the feed force $F x$, the feed is the main influencing factor, and cutting edge radius is the second. However, for the cutting force $F y$, the cutting edge radius is the main influencing factor and feed is the second influencing factor, followed by the cutting speed and rake angle. Cutting speed has no significant effect on the cutting forces.

- Response surface optimization shows that the optimal combination of machining parameters is for cutting speed $30 \mathrm{~m} / \mathrm{min}$, feed $0,05 \mathrm{~mm}$, cutting edge radius $20 \mu \mathrm{m}$ and rake angle $-15^{\circ}$, respectively. From the analysis results, the optimization values were obtained as $123.67 \mathrm{~N}$, $98.67 \mathrm{~N}$, and $379.33^{\circ} \mathrm{C}$ for the $F x$, Fy and $T$, respectively. Hence, RSM can better predict the effect of parameters on results and is a better method for optimization.

In the desirability function approach, the values of composite desirability were 1.0 and 1.0 for RSM model of Fx, Fy and T, respectively. Desirability function in the RSM method for the optimization of response is a very powerful tool for predicting cutting forces. For the reason that, the value of composite desirability is 1,000000, which representing functional statistical significance is $100 \%$.

\section{Acknowledgements}

This work was supported by the Slovak Research and Development Agency bilateral project under the contract SKAT-2015-0020 Integration of Nanometrological Process into Quality Assessment for Small Diameter of End Mill Cutters and the bilateral project APVV SK-SRB-2016-0045 Integration of artificial intelligence methods into innovative milling processes.

\section{References}

[1] RODRIGUEZ C.J.C.: Cutting edge preparation of precision cutting tools by applying micro-abrasive jet machining and brushing. Kassel University press GMBH. (2009) 189

[2] RECH J. et al.: Influence of cutting edge radius on the wear resistance of PM-HSS milling inserts. (2005), Wear, vol. 259, pp. 1168-1176.

[3] DENKENA B. et al.: Effects of the cutting edge micro geometry on tool wear and its thermo-mechanical load. (2011),
CIRP Journal of Manufacturing Science and Technology, Vol. $6073-6$.

[4] WYEN C.-F. et al.: Influence of cutting edge radius on cutting forces in machining titanium. (2010), CIRP-Man. Technology, vol. 59, pp. 93-96.

[5] BASSETT E. et al.: On the honed cutting edge and its side effects during orthogonal turning operations of AISI1045 with coated WC-Co inserts. (2012), CIRP J of Man. Scien and Technology, vol. 5, pp. 108-126.

[6] CALAMAZ M. et al.: A new material model for 2D numerical simulation of serrated chip formation when machining titanium alloy Ti-6Al-4V. (2008), Int. J of Machine Tools \& Manufacture vol. 48 pp. 275-288.

[7] UMBRELLO D.:; Finite element simulation of conventional and high speed machining of Ti6Al4V alloy. (2008), Journal Of Materials Processing Technology vol. 196, pp. 79-87.

[8] KUMAR N.S. et al.: Finite element analysis and optimization of uncoated carbide cutting inserts of different tool geometries in machining AISI 1045 steel. Journal of Mech. Sciens, Vol. 1 No. 1, pp 37-47.

[9] SASAHARA $\mathrm{H}$. et al.: Prediction model of surface residual stress within a machined surface by combining two orthogonal plane models. (2004), Int. Jl of Machine Tools and Manufacture, vol. 44, pp. 815-822.

[10] YEN Y. CH.: A finite element analysis of orthogonal machining using different tool edge geometries", (2002), Journal of materials processing technology, vol. 146, pp. 72-81.

[11] MATSUMURA T., TAMURA Sh.: Cutting simulation of titanium alloy drilling with energy analysis and FEM (2015) Proceedia CIRP 31 pp.252 - 257

[12] ULUTAN D. et al.: Determination of Tool Friction in Presence of Flank Wear and Stress Distribution Based Validation using Finite Element Simulations in Machining of Titanium and Nickel Based Alloys. (2013), J of Materials Processing Technology pp. 1 - 43.

[13] WYEN C.F. et al.: Influence of cutting edge radius on cutting forces in machining titanium. (2010), CIRP - Man. Technology vol. 59, pp. 93-96.

[14] CONSTANTIN C et al.: FEM tools for cutting process modelling and simulation. (2012), U.P.B. Sci. Bull., Series D, vol. 74, ISSN 1454-2358.

[15] ÖZEL T. et al.: Investigations on the effects of multi-layered coated inserts in machining Ti6Al4V alloy with experiments and finite element simulations. (2010), CIRP Manufacturing Technology vol. 59, pp. 77.

[16] LAZOGLU I, et al. Thermal analysis in Ti-6Al-4V drilling. CIRP Annals - Manufacturing Technology (2017), http://dx.doi. org/10.1016/j.cirp.2017.04.020

[17] MADADIA A.J. et al.: Optimisation of machining parameters for turning operations based on response surface method- 
ology. (2013), Measurement vol. 46, pp. 1521 - 1529.

[18] SARIKAYA M. et al.: Taguchi design and response surface methodology based analysis of machining parameters in CNC turning under MQL. (2013), Journal of Cleaner Production, pp. $1-40$.

\section{Biographical notes}

Marek Vrabel,' Ing., Ph.D., born 16th July 1985 in Prešov; graduated from Technical University of Košice, Faculty of Mechanical Engineering in the field of machining technology, in 2009. Position: Research fellow, Department of Manufacturing Technology and Materials; Specialization: Machining operations, Cutting tools, and Process Monitoring. Participated in several projects with national as well as international consortium. Attended several internships and short term visits all over the Europe (Sweden, Germay, Spain, UK a.0). Author and co-author of several publications in scientific databases (Current Contents, Scopus, WOS).

M. N. Durakbasa, Professor Dipl. Ing. Dr. techn. Prof. h.c. Dr. h.c., born: 21th May 1955 in K. Maras (TR). Experience in Quality Management Methods and Quality Engineering. Publications: 8 books, more than 320 scientific papers. More than 280 lectures in various European countries as well as in USA, Azerbaijan, Brazil, China, Cuba, Egypt, Japan, Kirghizstan, Korea, VAR and Turkey. Pavel Kovač, Prof., Ing. Dr., field of interest: Machining, Process monitoring, Virtual instrumentation, DoE, Sensor development, Artificial intelligence. Visiting professor on Prince of Sonkla University in Hatyai, Thailand (2006). Principal investigator of two Serbian national projects number TR14206 and TR35015. Participant in Serbian national projects number TR3203 and TR14030 and CEEPUS projects CII-SK-0405-02-1011, CII-SK-0067-06-1011, CII-PL-0007-06-1011.

IIdikó Maňková, Prof., Ing., CSc., graduated from Technical University of Kosice, Facuttly of Mechanical Engineering (1976), PhD thesis (1984), habilitation (1994), professor in the field of Manufacturing Technology and Materials (2005), Profesor honoris causae Facultatis Mechanicae Universitae Miskolc Hungary (2010). Research on procedures and ways of process and tool condition monitoring, studies in surface roughness in hard and precision machining, research on ceramic cutting insert and coated cutting carbide inserts wear behaviour and tool performance, application of statistical methods in measured data processing. 